\title{
Accelerometry of Seabream in a Sea-Cage: Is Acceleration a Good Proxy for Activity?
}

\author{
Arjan P. Palstra ${ }^{1 *}$, Pablo Arechavala-Lopez 2,3, Yuanxu Xue ${ }^{1}$ and Ana Roque ${ }^{4}$ \\ ${ }^{1}$ Wageningen University \& Research Animal Breeding and Genomics, Wageningen Livestock Research, Wageningen, \\ Netherlands, ${ }^{2}$ Fish Ecology Group, Mediterranean Institute of Advanced Studies (IMEDEA-CSIC/UIB), Esporles, Spain, ${ }^{3}$ Fish \\ Ethology and Welfare Group, Centro de Ciencias do Mar (CCMAR), Universidade do Algarve, Faro, Portugal, ${ }^{4}$ IRTA- SCR, \\ Sant Carles de la Rapita, Spain
}

\section{OPEN ACCESS}

Edited by:

Morten Omholt Alver, Norwegian University of Science and Technology, Norway

Reviewed by: Leonardo Julián Magnoni, University of Porto, Portugal Gabriel Cardenete, University of Granada, Spain

*Correspondence: Arjan P. Palstra arjan.palstra@wur.nl

Specialty section: This article was submitted to Marine Fisheries, Aquaculture and Living Resources, a section of the journal

Frontiers in Marine Science

Received: 09 December 2020 Accepted: 04 February 2021

Published: 22 February 2021

Citation:

Palstra AP, Arechavala-Lopez P,

$X u e Y$ and Roque A (2021) Accelerometry of Seabream in a Sea-Cage: Is Acceleration a Good Proxy for Activity?

Front. Mar. Sci. 8:639608. doi: 10.3389/fmars.2021.639608
Activity assessment of individual fish in a sea-cage could provide valuable insights into the behavior, but also physiological well-being and resilience, of the fish population in the cage. Acceleration can be monitored continuously with internal acoustic transmitter tags and is generally applied as a real-time proxy for activity. The objective of this study was to investigate the activity patterns of Gilthead seabream (Sparus aurata) by transmitter tags in a sea-cage and analyze correlations with water temperature, fish size and tissue weights. Experimental fish $(N=300)$ were transferred to an experimental sea-cage of which thirty fish (Standard Length SL = $18.3 \pm 1.7 \mathrm{~cm}$; Body Weight BW = $174 \pm 39 \mathrm{~g}$ ) were implanted with accelerometer tags. Accelerations were monitored for a period of 6 weeks (Nov.-Dec.) and were analyzed over the 6 weeks and $24 \mathrm{~h}$ of the day. At the end of the experimental period, tagged fish were again measured, weighed and dissected for tissue and filet weights, and correlations with accelerations were analyzed. Daily rhythms in accelerations under the experimental conditions were characterized by more active periods from 6 to $14 \mathrm{~h}$ and 18 to $0 \mathrm{~h}$ and less active periods from 0 to $6 \mathrm{~h}$ and 14 to $18 \mathrm{~h}$. This $\mathrm{W}$-shaped pattern remained over the experimental weeks, even with diurnal accelerations decreasing which was correlated to the dropping temperature. The increase in activity was not during, but just before feeding indicating food-anticipatory activity. Activity patterning can be useful for timing feeding events at the start of active periods, in this study between 6 and $11 \mathrm{~h}$, and between 18 and $22 \mathrm{~h}$. Acceleration was negatively correlated to heart and mesenteric fat mass, which was the exact contrary of our expectations for sustainedly swimming seabream. These results suggest that acceleration is a proxy for unsteady swimming activity only and research is required into the accelerations occurring during sustained swimming of seabream at various speeds.

Keywords: aquaculture, telemetry, acoustic transmitter tags, activity monitoring, swimming behavior

\section{INTRODUCTION}

Monitoring the physiological well-being of fish in a sea-cage is a difficult but pivotal task for health management and assessment of the impact of preventive health measures. Activity assessment of individual (marker) fish in the cage can shed light on these issues as well as on their energy metabolism and environmental interactions. Acceleration can be monitored continuously with 
internal acoustic transmitter tags and applied as a proxy for activity (de Almeida et al., 2013). Accelerometry has been performed on Atlantic salmon in recirculating aquaculture systems (RAS; Kolarevic et al., 2016) and in floating sea-cages (Føre et al., 2011, 2018). Activity patterning by accelerometry on Gilthead seabream has been performed recently (Muñoz et al., 2020) and could represent a valuable tool for real time monitoring of fish welfare also for this species.

Gilthead seabream (Sparus aurata) is currently the most important species in Mediterranean aquaculture. Like Atlantic salmon, seabream is raised on-land in RAS or flow through systems until they are transferred to sea-cages. In the sea cage, seabream activity is influenced by the photothermal conditions (Bégout and Lagardère, 1995), feeding regime (Andrew et al., 2002; López-Olmeda et al., 2009) and stress inducers, factors that may be interrelated (Andrew et al., 2002; Sánchez et al., 2009). Furthermore, seabream activity is characterized by sustained swimming behavior during daytime (Sánchez et al., 2009). These fish school and swim in circles (Martins et al., 2012) indicating that sustained swimming exercise is part of their innate behavior contributing to their physiological well-being. Scientific research on the, potentially beneficial, effects of sustained swimming exercise on growth, stress, health, and reproduction has received increasing attention over the past decade for an extending range of species (Palstra and Planas, 2011, 2013; Planas et al., 2017; McKenzie et al., 2020).

Activity of seabream in a sea cage is associated with their swimming behavior. Seabream is a well performing swimmer with a critical swimming speed of $101.5 \pm 9.4 \mathrm{~cm} \mathrm{~s}^{-1}$ or $9.1 \pm 0.7 \mathrm{SL} \mathrm{s}^{-1}$ as determined in an incremental exercise load

TABLE 1 | Biometry, tissue weights, and indices of tagged fish at the start $(N=30)$ and at the end of the 6 weeks sea-cage period $(N=27)$.

\begin{tabular}{|c|c|c|c|}
\hline & & AV & SD \\
\hline \multirow[t]{3}{*}{ Start } & SL & 18.3 & 1.7 \\
\hline & BW & 174 & 39 \\
\hline & K & 2.85 & 0.38 \\
\hline \multirow[t]{17}{*}{ End } & SL & 19.2 & 1.2 \\
\hline & BW & 221 & 44 \\
\hline & $\mathrm{K}$ & 3.11 & 0.35 \\
\hline & FW & 60.8 & 13.3 \\
\hline & $\mathrm{HW}$ & 0.31 & 0.07 \\
\hline & LW & 5.42 & 1.79 \\
\hline & IW & 5.51 & 1.07 \\
\hline & SW & 0.44 & 0.16 \\
\hline & MFW & 1.59 & 0.67 \\
\hline & $\mathrm{CW}$ & 195.3 & 39.8 \\
\hline & $\mathrm{FI}$ & 27.5 & 1.1 \\
\hline & $\mathrm{HI}$ & 0.139 & 0.019 \\
\hline & $\mathrm{HSI}$ & 2.45 & 0.55 \\
\hline & $\|$ & 2.53 & 0.41 \\
\hline & $\mathrm{SI}$ & 0.201 & 0.066 \\
\hline & $\mathrm{MFI}$ & 0.711 & 0.226 \\
\hline & $\mathrm{Cl}$ & 88.4 & 2.2 \\
\hline
\end{tabular}

AV, average; SD, standard deviation. For parameter abbreviations see text. test for juvenile fish $(11.2 \pm 1.0 \mathrm{~cm} \mathrm{SL}, 36.5 \pm 9.4 \mathrm{~g} \mathrm{BW}$; Palstra et al., 2020a). Seabream is able to swim continuously at optimal swimming speeds for long-term periods (e.g., 24 days swimming at an optimal speed of $67 \mathrm{~cm} \mathrm{~s}^{-1}$, or $3.59 \mathrm{BL} \mathrm{s}^{-1}$, for fish of $\sim 20 \mathrm{~cm} \mathrm{SL}$, and $\sim 200 \mathrm{~g} \mathrm{BW}$; Palstra and Graziano, unpublished data). However, at lower swimming speeds of 1-2 BL $s^{-1}$, fish benefit optimally from enhanced (muscle) growth (Ibarz et al., 2011; Palstra et al., 2020b) and physiological wellbeing indicated by lower baseline plasma cortisol levels, higher condition factors, larger hearts and increased plasma glucose (Palstra et al., 2020b). These results show that the more active and sustained swimming fish will resemble the features of such trained athletes including a more hydrodynamic and leaner body shape (Koumoundouros et al., 2009) with less mesenteric fat (similar to fast growing seabream; Simó-Mirabet et al., 2018), and a larger heart with higher pumping capacity and cardiac output (Farrell, 1991; Farrell et al., 2007, 2009; Rodnick and Planas, 2016). We hypothesize that these fish also show higher acceleration levels, i.e., that the acceleration levels reflect the general swimming activity (Kolarevic et al., 2016; Føre et al., 2018; Muñoz et al., 2020).

In this study the activity patterns of Gilthead seabream (Sparus aurata) were investigated in a sea-cage. For this purpose, fish were recorded continuously during a 6 weeks period by accelerometry. Activity patterns were analyzed $24 \mathrm{~h}$ per day over the 6 experimental weeks and, at the end of the trial, linked to growth, tissue weights and biometric parameters.

\section{MATERIALS AND METHODS}

\section{Ethics}

All methods were performed in accordance with the relevant guidelines and regulations. Experimental work was approved by the Animal Experimental Commission of the Autonomous Government of Catalonia with protocol number 10323 and fish were always carefully handled by accredited staff.

\section{Experimental Fish and Accelerometry}

Experimental fish $(N=300)$ were raised in a flow-through system at IRTA facilities (Sant Carles de la Ràpita, Spain) at a water temperature of $18^{\circ} \mathrm{C}$, salinity of $35 \mathrm{ppt}$ and under natural photoperiod. Fish were manually fed twice per day ad libitum with commercial seabream pellets (Skretting, Spain). Fish were transferred to LIMIA facilities (Port d'Andratx, Spain) where the next day thirty fish (Standard Length SL $=18.3 \pm 1.7 \mathrm{~cm}$; Body Weight $\mathrm{BW}=174 \pm 39$ g; Table 1) were randomly selected and implanted with accelerometer tags. Accelerometer tags ("AccelTag" AT-LP7; Figure 1A; $21 \times 7.3 \mathrm{~mm} ; 1.9 \mathrm{~g}$ in air, $1 \mathrm{~g}$ in water; Thelmabiotel, Trondheim, Norway) were used that record every $60 \mathrm{~s}$ the gravity forces and movement along the three axes which can be converted to acceleration in $\mathrm{m} \mathrm{s}^{-2}$. Fish were anesthetized by submersion in an aqueous solution of tricaine methane sulfonate (MS-222, $75 \mathrm{mg} \mathrm{L}^{-1}$ ) for $4 \mathrm{~min}$ at $15-17^{\circ} \mathrm{C}$. Once anesthetized, the fish were measured, weighed, and placed with the ventral side up on a surgical table to implant the transmitter tags (Figure 1A). For this purpose, an 
incision $(\sim 1 \mathrm{~cm})$ was made on the ventral surface, posterior to the pelvic girdle, through which the transmitter tag was introduced into the body cavity. The incision was closed with two or three independent silk sutures. Each surgery took 23 min during which the fish were regularly sprayed with water. Before each incision, the surgical equipment was rinsed in
$70 \%$ ethanol and dried. This tagging procedure and technique has been successfully applied in previous studies on Gilthead seabream (Arechavala-Lopez et al., 2012; Šegvić-Bubić et al., 2018; Muñoz et al., 2020). After surgery, the fish were allowed to recover in a tank for $48 \mathrm{~h}$ and then all fish were transferred to the experimental sea-cage (Figure 1B). Recordings were
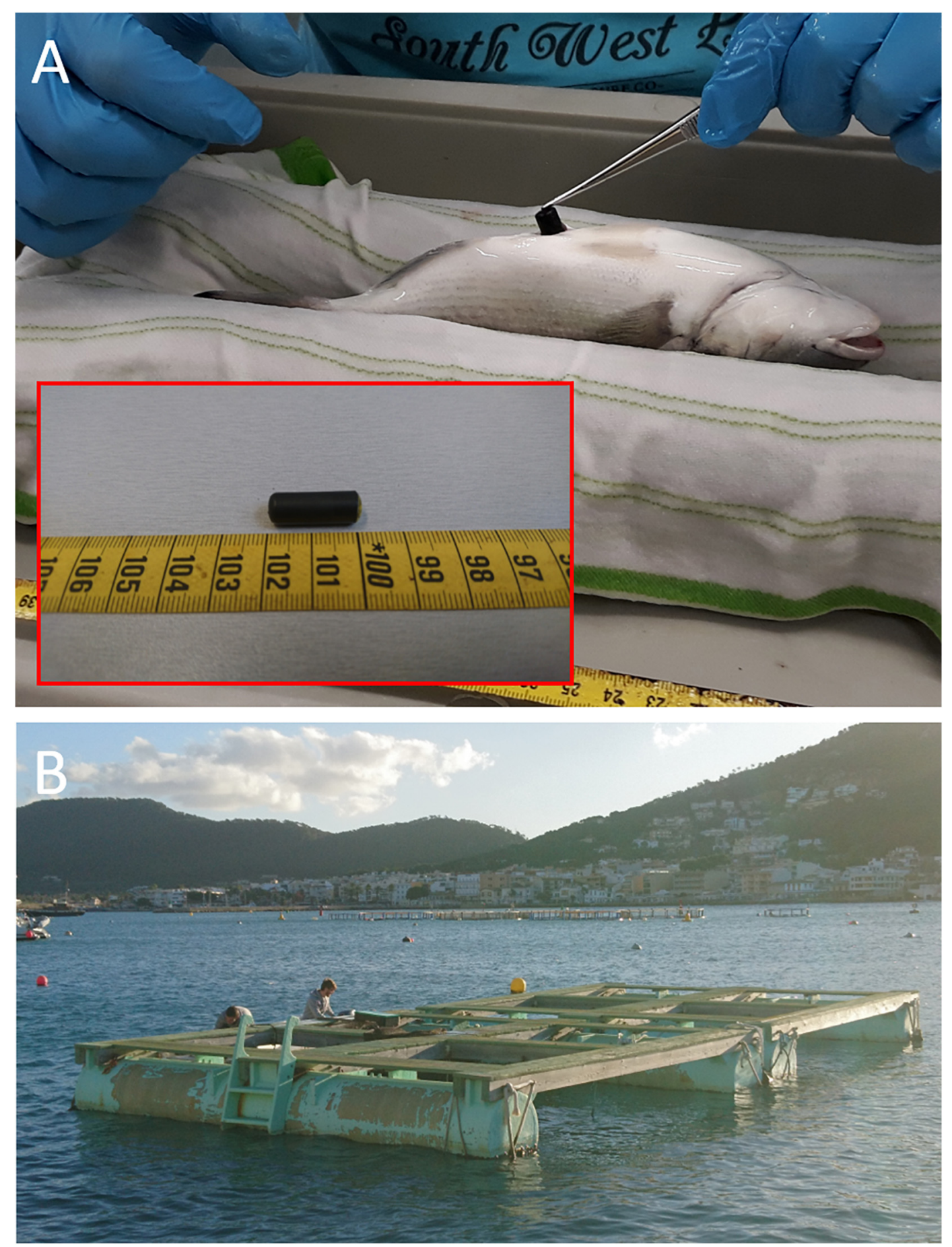

FIGURE 1 | (A) Seabream surgery to implant the tag; insert: tag size, (B) the experimental sea-cage. 


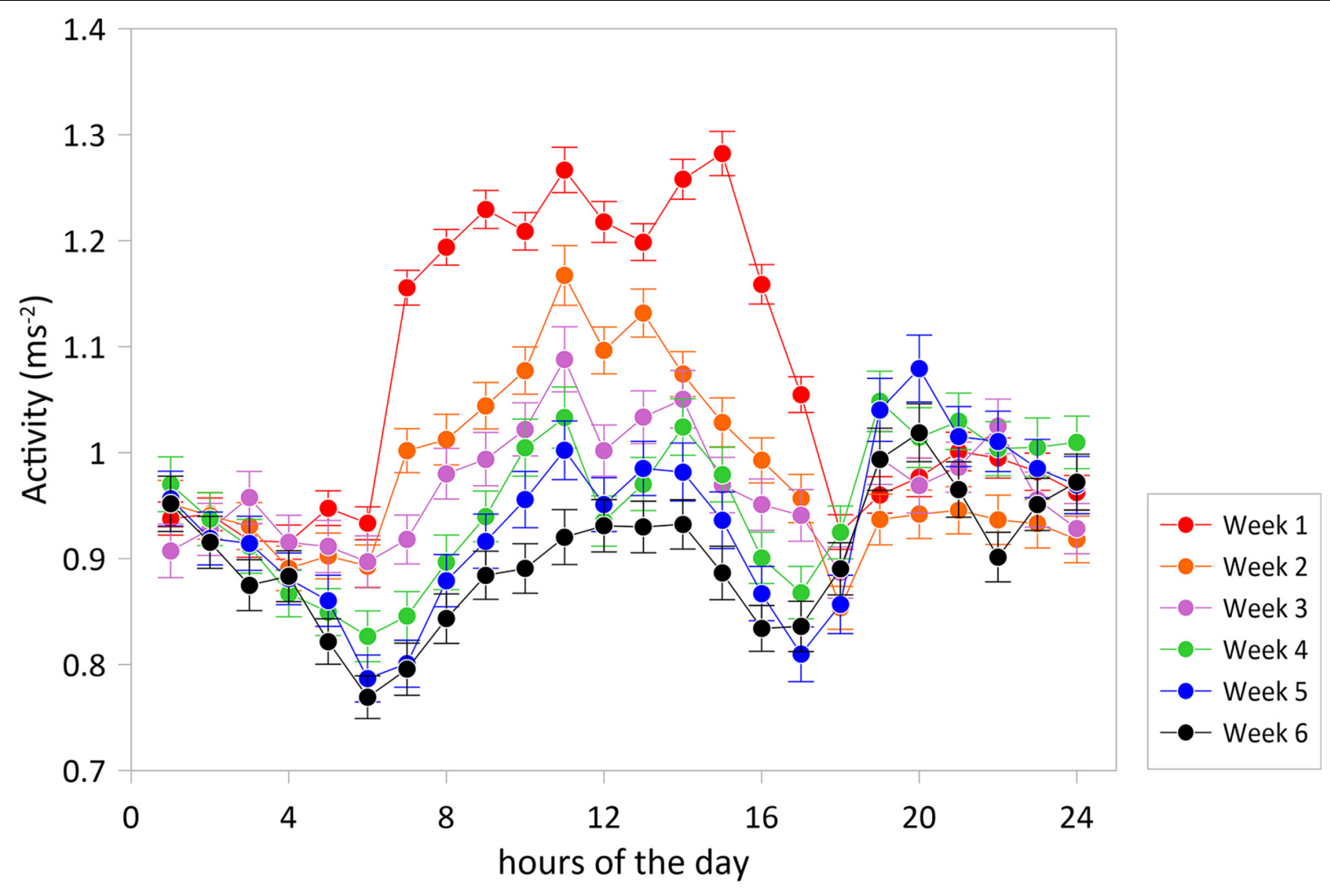

FIGURE 2 | Average accelerations ( \pm SE) over the hours of the day for experimental weeks $1-6$. The graph shows a typical W-shaped pattern with more active periods from 6 to $14 \mathrm{~h}$ and 18 to $0 \mathrm{~h}$ and less active periods from 0 to $6 \mathrm{~h}$ and 14 to $18 \mathrm{~h}$ and with diurnal accelerations decreasing toward the winter. The experimental period was started with $N=30$ tagged fish, three fish were lost in action.

monitored by one receiver (TBR700; Thelmabiotel) placed at the bottom of the cage.

\section{Monitoring Activity in the Sea-Cage}

Activity patterns were monitored for a period of 6 weeks (Nov.-Dec., with decreasing temperatures from max. 17.9 to min. $15.5^{\circ} \mathrm{C}$ ) in a cubic $2 * 2 * 2 \mathrm{~m}$ experimental sea-cage (fish density $\sim 10 \mathrm{~kg} \mathrm{~m}^{-3}$; Figure 1B). Three fish were lost in action: two Acceltags kept recording 0 values and another one disappeared from the reach of the receiver. In total, 182,098 recordings were collected. Fish were fed manually once per day ad libitum in the morning at $11 \mathrm{~h}$ with a commercial feed (Skretting seabream D4).

\section{Measurements and Tissue Dissection}

After the 6 weeks period, the remaining tagged fish $(N=30-$ $3=27$ ) were collected, sacrificed by an overdose anesthetic (MS222 at a concentration of a 105 ppm), measured, weighed, and heart, liver, intestine, spleen, mesenteric fat, and filet were dissected and weighed. Filets were sliced away from the bone on one side of the fish from front to tail end and extending along a longitudinal axis, all under experienced supervision. Tissue weights were calculated relative to body weight and expressed as weight indices (filet weight - FW; heart weight -
HW; liver weight - LW; intestine weight - IW; spleen weight SW; mesenteric fat weight - MFW; carcass weight - CW; filet index - FI; heart index - HI; hepatosomatic index - HSI; intestine

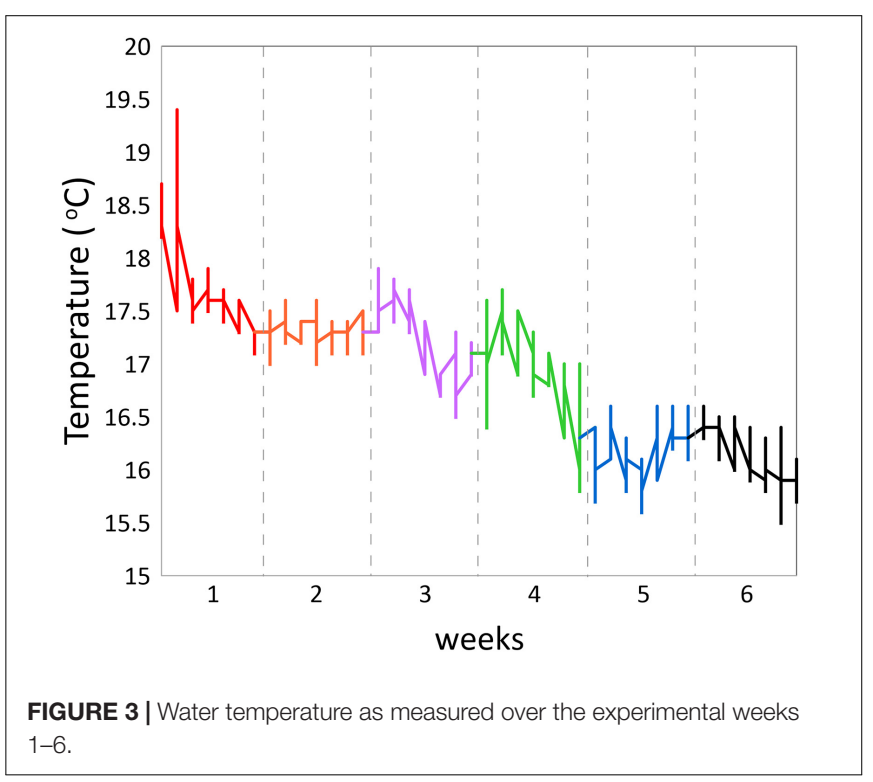


TABLE 2 | Regression coefficients and normalized regression coefficients of acceleration vs. filet weight (FW); carcass weight (CW); heart weight (HW); spleen weight (SW); liver weight (LW); intestine weight (IW); and mesenteric fat weight (MFW), with body weight (BW) as cofactor and providing the interaction effect between cofactor and dependent parameter.

\begin{tabular}{|c|c|c|c|}
\hline $\begin{array}{l}\text { Regression } \\
\text { coefficient of } \\
\text { acceleration with }\end{array}$ & Dependent & Cofactor BW (start) & Interaction \\
\hline FW & $-8.010 e-03$ & $-2.219 e-03$ & $3.313 e-05$ \\
\hline $\mathrm{CW}$ & $-3.437 e-03$ & $-1.400 e-03$ & $1.024 e-05$ \\
\hline $\mathrm{HW}$ & -1.630100 & -0.004331 & 0.009903 \\
\hline SW & 0.7806184 & 0.0005287 & -0.0035244 \\
\hline LW & $8.402 e-04$ & $-2.127 e-03$ & $1.438 e-04$ \\
\hline IW & -0.3645735 & -0.0114289 & 0.0021401 \\
\hline MFW & 0.1043879 & -0.0006215 & -0.0004877 \\
\hline $\begin{array}{l}\text { Normalized } \\
\text { regression } \\
\text { coefficient of } \\
\text { acceleration with }\end{array}$ & Dependent & Cofactor BW (start) & Interaction \\
\hline FW & -0.087377 & -0.041832 & 0.028772 \\
\hline CW & -0.145048 & 0.025417 & 0.025425 \\
\hline $\mathrm{HW}$ & -0.021600 & -0.108725 & 0.033198 \\
\hline SW & 0.088753 & -0.077681 & -0.038085 \\
\hline LW & 0.040627 & -0.111693 & 0.009269 \\
\hline IW & -0.063040 & -0.071066 & 0.076855 \\
\hline MFW & 0.035779 & -0.101212 & -0.016953 \\
\hline
\end{tabular}

Values in bold indicate significance at $P<0.05$.

index - II; spleen index - SI; mesenteric fat index - MFI; carcass index - CI).

\section{Statistics}

Statistical analyses were performed with IBM SPSS 25 software. Acceleration data were normally distributed over the 6 experimental weeks and $24 \mathrm{~h}$ of the day. Differences in activity patterns were statistically tested using one-way ANOVA with Tukey post-hoc correction. Correlations of accelerations vs. temperature, and paired accelerations vs. tissue weights with body weight as a cofactor, were analyzed in R. Two types of linear regression models were used to evaluate the correlation, considering the interaction. The variables were standardized and normalized to a mean of 0 and standard deviation of 1 in one type, and used without normalization in another. The difference was that, when using normalized data, the correlation coefficient is independent regardless of the actual range of data; when using the data without preprocessing, the correlation coefficient reflects not only if the relationship between variables was significant but also how strong the relationship was. $P \leq 0.05$ was considered significant.

\section{RESULTS AND DISCUSSION}

Accelerations of Gilthead seabream (Sparus aurata) in a sea-cage were monitored continuously with internal acoustic transmitter tags over a 6 weeks period and used as a proxy for activity.
Activity patterns were analyzed over the 6 weeks and $24 \mathrm{~h}$ of the day and accelerations were analyzed for correlations with water temperature and tissue weights. The average recorded acceleration value was $0.96 \pm 0.36 \mathrm{~m} \mathrm{~s}^{-2}$, ranging from zero to $3.47 \mathrm{~m} \mathrm{~s}^{-2}$. On the level of individual fish, average acceleration was $1.03 \pm 0.06 \mathrm{~m} \mathrm{~s}^{-2}$, comparable to the acceleration values reported by Muñoz et al. (2020). The least active fish had an average acceleration of $0.94 \pm 0.23 \mathrm{~m} \mathrm{~s}^{-2}$, the most active fish of $1.21 \pm 0.34 \mathrm{~m} \mathrm{~s}^{-2}$, showing a considerable range of individual variation.

Daily rhythms in swimming activity under the experimental conditions were characterized by more active periods from 6 to $14 \mathrm{~h}$ and 18 to $0 \mathrm{~h}$ and less active periods from 0 to $6 \mathrm{~h}$ and 14 to $18 \mathrm{~h}$ (Figure 2). Acceleration level was lowest at $6 \mathrm{~h}$ $(P<0.001)$ and highest at $11 \mathrm{~h}(P<0.001)$ and $14 \mathrm{~h}(P<0.01)$, time points that significantly differed from any other timepoint. This W-shape activity pattern over the hours of the day agrees with the recent findings of Muñoz et al. (2020) for 10 seabreams in a larger experimental cage over 25 days in May. Thus, this pattern is valid for two opposite periods of the year, spring and autumn, but comparable in water temperature, light:dark periods and light intensities. The $\mathrm{W}$-shaped pattern was found for each of the six consecutive experimental weeks and was thus independent of water temperatures that showed a drop between maximum values of $17.9^{\circ} \mathrm{C}$ at the start in the beginning of November down to $15.5^{\circ} \mathrm{C}$ at the end of the experimental period (Figure 3).

However, the acceleration levels, particularly during the more active period of the day, dropped with each experimental week which may well be related to the decreasing water temperature. Acceleration was positively correlated with water temperature (regression coefficient $0.398 ; P=0.0295$ ) showing that water temperature was, at least partly, responsible for decreasing the acceleration levels. Besides the positive correlation between acceleration and temperature over the weeks, part of the higher activity level in the first week may be explained by higher stress levels during habituation related to the confinement as also the standard deviations were lower than those in the following weeks (Figure 2). In week 4 (Nov. 23-29), highest acceleration levels were similar between noon and evening after which acceleration levels started to be lower at noon than in the evening. This reflects that fish reduce daytime activity toward the winter period instead of becoming more nocturnal as described in earlier studies (Paspatis et al., 2000; Velázquez et al., 2004; Vera et al., 2014; Paredes et al., 2014).

The increase in daily activity was not during, but just before feeding indicating that experimental fish may have good ability to predict and time a re-occurring event such as feeding. Such foodanticipatory activity has been established for Gilthead seabream (Sánchez et al., 2009) and other cultured fish species, such as Atlantic salmon, cod, and halibut (Nilsson et al., 2008, 2010; Folkedal et al., 2012, respectively). Enabling fish to physiologically prepare for a forthcoming feed is considered as beneficial for their welfare (Sánchez et al., 2009). Feeding time(s) should therefore be timed strictly.

Activity patterning can be useful for timing feeding events. Both meal timing and the number of meals can improve the growth performance of aquaculture species (reviewed by 
López-Olmeda et al., 2012). Under the environmental conditions of our study, it would be advisable to feed seabream at the start of active periods; for example, between 6 and $11 \mathrm{~h}$, and between 18 and 22 h. A customized feeding strategy that coincides with increased activity may not only improve growth performance in general, but also specifically favor muscle building at the cost of mesenteric fat deposition. This will significantly increase feeding efficiency in terms of filet yield.

Table 1 presents the biometric measurements, tissue weights and indices of the tagged fish at the end of the 6 weeks sea-cage period. Fish had grown in length $(+4.9 \%)$ and weight $(+27.0 \%)$. Acceleration (paired values per individual) was negatively correlated to heart and intestine mass, and positively to spleen and mesenteric fat mass. Regression coefficients of accelerations vs. HW, IW, SW, and MFW (Table 2) were significant and biologically relevant but weak when the normalized regression coefficient was considered. Based on the different results of the two regression models, we speculate that HW, IW, SW, and MFW influence accelerations directly and through the interaction with BW. The negative correlation between acceleration and $\mathrm{HW}$, and positive correlation between acceleration and MFW, represent the exact contrary of our expectations for sustained swimming seabream that have been trained by long-term exercise and therefore we must reject our hypothesis. Either the more active fish are characterized by smaller hearts and more mesenteric fat mass, or accelerations are not a good proxy for general activity. The first assumption is highly unlikely as we recently found that swimming exercise training in seabream increased heart mass (Palstra et al., 2020b), which agrees with results on exerciseinduced cardiac hypertrophy for many other fishes (reviewed by Gamperl and Farrell, 2004; Takle and Castro, 2013; Rodnick and Planas, 2016) and mammals (Nakamura and Sadoshima, 2018). Exercised seabream is also leaner with less mesenteric fat than non-exercised fish (Blasco et al., 2015). In an unpublished study where we exercised seabream for 24 days at a speed of $0.67 \mathrm{~m} \mathrm{~s}^{-1}$ as compared to fish that rested, the heart index was higher $(0.16$ vs. 0.12 ) and the mesenteric (intestinal) fat index was lower (1.29 vs. 1.87 for fish of $\sim 200 \mathrm{~g}$; Palstra and Graziano, unpublished data). This would then indicate that the second assumption is more realistic, and that acceleration is not a proxy for sustained swimming exercise but unsteady swimming activity only, caused for example by escape responses as a result of stress or aggressive behavior, foraging behavior, or burst-and-glide swimming. From our data we cannot deduce how periods of higher or lower activity may relate to differences in swimming mode e.g., schooling in circles or random swimming. Research is therefore required

\section{REFERENCES}

Andrew, J. E., Noble, C., Kadri, S., Jewell, H., and Huntingford, F. A. (2002). The effect of demand feeding on swimming speed and feeding responses in Atlantic salmon Salmo salar L., gilthead sea bream Sparus aurata L. and European sea bass Dicentrarchus labrax L. is sea cages. Aquac. Res. 33, 501-507.

Arechavala-Lopez, P., Uglem, I., Fernandez-Jover, D., Bayle-Sempere, J. T., and Sanchez-Jerez, P. (2012). Post-escape dispersion of farmed seabream (Sparus aurata L.) and recaptures by local fisheries in the Western Mediterranean Sea. Fish. Res. 121, 126-135.

Bégout, M. L., and Lagardère, J. P. (1995). "An acoustic telemetry study of seabream (Sparus aurata L.): first results on activity rhythm, effects of environmental into the accelerations occurring during sustained swimming of seabream at various speeds in controlled surroundings such as in swim-tunnels which is topic of our current investigations.

\section{DATA AVAILABILITY STATEMENT}

The raw data supporting the conclusions of this article will be made available by the authors, without undue reservation, to any qualified researcher.

\section{ETHICS STATEMENT}

The animal study was reviewed and approved by the Animal Experimental Commission of the Autonomous Government of Catalonia.

\section{AUTHOR CONTRIBUTIONS}

AP, PA-L, and AR: conception and design of the study and acquisition of data. AP, PA-L, YX, and AR: analysis and interpretation of data, drafting the manuscript, and reviewing. All authors read and approved the final manuscript.

\section{FUNDING}

This work was supported by the EU H2020 RIA MedAID (Grant No. 727315). The funding source had no involvement in the conducted research and/or preparation of the article. Additionally, this study received Portuguese national funds from FCT - Foundation for Science and Technology through project UIDB/04326/2020.

\section{ACKNOWLEDGMENTS}

We thank A. Leon Delgado (LIMIA/IMEDEA) for feeding, animal care, and data collection; E. Høy and A. Haugsdal (Thelmabiotel) for their valuable help with starting up the AccelTags; P. Jéhannet, and L. Kruijt for lab analyses (WUR); C. Diaz-Gil for mastering flesh fileting, and zootechnicians, students, and research assistants at IRTA, LIMIA/IMEDEA, and CARUS. More info on swimming fish @ www.fitfish.eu.

variables and space utilization," in Developments in Hydrobiology. Space Partition within Aquatic Ecosystems, ed. G. Balvay, (Heidelberg: Springer), 417-423. doi: 10.1007/978-94-011-0293-3_40

Blasco, J., Moya, A., Millán-Cubillo, A., Vélez, E. J., Capilla, E., Pérez-Sánchez, J., et al. (2015). Growth-promoting effects of sustained swimming in fingerlings of gilthead sea bream (Sparus aurata L.). J. Comp. Physiol. B 185, 859-868. doi: 10.1007/s00360-015-0933-5

de Almeida, P. R., Pereira, T. J., Quintella, B. R., Gronningsaeter, A., Costa, M. J., and Costa, J. L. (2013). Testing a 3-axis accelerometer acoustic transmitter (AccelTag) on the Lusitanian toadfish. J. Exp. Mar. Biol. Ecol. 449, 230-238. doi: 10.1016/j.jembe.2013. 09.015 
Farrell, A. P. (1991). From hagfish to tuna: a perspective on cardiac function in fish. Physiol. Zool. 64, 1137-1164. doi: 10.1086/physzool.64.5.3015 6237

Farrell, A. P., Axelsson, M., Altimiras, J., Sandblom, E., and Claireaux, G. (2007). Maximum cardiac performance and adrenergic sensitivity of the sea bass Dicentrarchus labrax at high temperatures. J. Exp. Biol. 210, 1216-1224. doi: 10.1242/jeb.002881

Farrell, A. P., Eliason, E. J., Sandblom, E., and Clark, T. D. (2009). Fish cardiorespiratory physiology in an era of climate change. Can. J. Zool. 87, 835-851.

Folkedal, O., Stien, L. H., Torgersen, T., Oppedal, F., Olsen, R. E., Fosseidengen, J. E., et al. (2012). Food anticipatory behaviour as an indicator of stress response and recovery in Atlantic salmon post-smolt after exposure to acute temperature fluctuation. Physiol. Behav. 105, 350-356. doi: 10.1016/j.physbeh.2011. 08.008

Føre, M., Alfredsen, J. A., and Gronningsater, A. (2011). Development of two telemetry-based systems for monitoring the feeding behaviour of Atlantic salmon (Salmo salar L.) in aquaculture sea-cages. Comput. Electron. Agric. 76, 240-251. doi: 10.1016/j.compag.2011.02.003

Føre, M., Svendsen, E., Alfredsen, J. A., Uglem, I., Bloecher, N., Sveier, H., et al. (2018). Using acoustic telemetry to monitor the effects of crowding and delousing procedures on farmed Atlantic salmon (Salmo salar). Aquaculture 495, 757-765. doi: 10.1016/j.aquaculture.2018.06.060

Gamperl, A. K., and Farrell, A. P. (2004). Cardiac plasticity in fishes: environmental influences and intraspecific differences. J. Exp. Biol. 207, 2539-2550. doi: 10. 1242/jeb.01057

Ibarz, A., Felip, O., Fernández-Borràs, J., Martín-Pérez, M., Blasco, J., and Torrella, J. R. (2011). Sustained swimming improves muscle growth and cellularity in gilthead sea bream. J. Comp. Physiol. B 181, 209-217. doi: 10.1007/s00360-0100516-4

Kolarevic, J., Aas-Hansen, Ø, Espmark, Å, Baeverfjord, G., Fyhn Terjesen, B., and Damsgård, B. (2016). The use of acoustic acceleration transmitter tags for monitoring of Atlantic salmon swimming activity in recirculating aquaculture systems (RAS). Aquacult. Eng. 72-73, 30-39. doi: 10.1016/j.aquaeng.2016.03. 002

Koumoundouros, G., Ashton, C., Xenikoudakis, G., Giopanou, I., Georgakopoulou, E., and Stickland, N. (2009). Ontogenetic differentiation of swimming performance in gilthead seabream (Sparus aurata, Linnaeus 1758) during metamorphosis. J. Exp. Mar. Biol. Ecol. 370, 75-81. doi: $10.1016 /$ j.jembe.2008.12.001

López-Olmeda, J. F., Montoya, A., Oliveira, C., and Sánchez-Vázquez, F. J. (2009). Synchronization to light and restricted feeding schedules of behavioral and humoral daily rhythms in gilthead seabream (Sparus aurata). Chronobiol. Int. 26, 1389-1408. doi: 10.3109/07420520903421922

López-Olmeda, J. F., Noble, C., and Sánchez-Vázquez, F. J. (2012). Does feeding time affect fish welfare? Fish. Physiol. Biochem. 38, 143-152. doi: 10.1007/97894-007-5383-9_9

Martins, C. I. M., Galhardo, L., Noble, C., Damsgård, B., Spedicato, M. T., Zupa, W., et al. (2012). Behavioural indicators of welfare in farmed fish. Fish. Physiol. Biochem. 38, 17-41. doi: 10.1007/978-94-007-5383-9_3

McKenzie, D. J., Palstra, A. P., Planas, J., MacKenzie, S., Bégout, M.-L., Thorarensen, H., et al. (2020). Aerobic swimming in intensive aquaculture: applications for production, mitigation and selection. Rev. Aquacult. 13, 138155. doi: 10.1111/raq.12467

Muñoz, L., Aspillaga, E., Palmer, M., Saraiva, J. L., and Arechavala-Lopez, P. (2020). Acoustic telemetry: a tool to monitor fish swimming behavior in sea-cage aquaculture. Front. Mar. Sci. 7:645. doi: 10.3389/fmars.2020. 00645

Nakamura, M., and Sadoshima, J. (2018). Mechanisms of physiological and pathological cardiac hypertrophy. Nat. Rev. Cardiol. 15, 387-407. doi: 10.1038/ s41569-018-0007-y

Nilsson, J., Kristiansen, T. S., Fosseidengen, J. E., Fernö, A., and van den Bos, R. (2008). Sign- and goal-tracking in Atlantic cod (Gadus morhua). Anim. Cogn. 11, 651-659. doi: 10.1007/s10071-008-0155-2
Nilsson, J., Kristiansen, T. S., Fosseidengen, J. E., Fernö, A., and van den Bos, R. (2010). Learning and anticipatory behaviour in a "sit-and-wait" predator: the Atlantic halibut. Behav. Processes 83, 257-266. doi: 10.1016/j.beproc.2009.12. 008

Palstra, A. P., Kals, J., Böhm, T., Bastiaansen, J., and Komen, H. (2020a). Swimming performance and oxygen consumption as non-lethal indicators of production traits in Atlantic salmon Salmo salar and gilthead seabream Sparus aurata. Front. Physiol. 11:759. doi: 10.3389/fphys.2020.00759

Palstra, A. P., and Planas, J. V. (2011). Fish under exercise. Fish Physiol. Biochem. 37, 259-272. doi: 10.1007/s10695-011-9505-0

Palstra, A. P., and Planas, J. V. (2013). Swimming Physiology of Fish. Towards Using Exercise to Farm a Fit Fish in Sustainable Aquaculture. Heidelberg: Springer.

Palstra, A. P., Roque, A., Kruijt, L., Jéhannet, P., Pérez Sanchez, J., and Dirks, R. P. (2020b). Physiological effects of water flow induced swimming exercise in seabream Sparus aurata. Front. Physiol. 11:610049. doi: 10.3389/fphys.2020. 610049

Paredes, J. F., Vera, L. M., Martinez-Lopez, F. J., Navarro, I., and Sánchez Vázquez, F. J. (2014). Circadian rhythms of gene expression of lipid metabolism in Gilthead seabream liver: synchronisation to light and feeding time. Chronobiol. Int. 31, 613-626. doi: 10.3109/07420528.2014.881837

Paspatis, M., Maragoudaki, D., and Kentouri, M. (2000). Self-feeding activity patterns in gilthead sea bream (Sparus aurata), red porgy (Pagrus pagrus) and their reciprocal hybrids. Aquaculture 190, 389-401. doi: 10.1016/s00448486(00)00409-9

Planas, J. V., Palstra, A. P., and Magnoni, L. J. (2017). Physiological Adaptations to Swimming in Fish. Lausanne: Frontiers Media.

Rodnick, K. J., and Planas, J. V. (2016). "The stress and stress mitigation effects of exercise: cardiovascular, metabolic, and skeletal muscle adjustments," in Fish Physiology. Biology of Stress in Fish, Vol. 35, eds C. B. Schreck, L. Tort, A. P. Farrell, and C. J. Brauner, (San Diego, CA: Academic Press), 251-294. doi: 10.1016/b978-0-12-802728-8.00007-2

Sánchez, J. A., López-Olmeda, J. F., Blanco-Vives, B., and Sánchez-Vázquez, F. J. (2009). Effects of feeding schedule on locomotor activity rhythms and stress response in sea bream. Physiol. Behav. 98, 125-129. doi: 10.1016/j.physbeh. 2009.04.020

Šegvić-Bubić, T., Arechavala-Lopez, P., Vučić, I., Talijančić, I., Grubišić, L., Žužul, I., et al. (2018). Site fidelity of farmed gilthead seabream Sparus aurata escapees in a coastal environment of the Adriatic Sea. Aquacult. Env. Interac. 10, 21-34. doi: 10.3354/aei00251

Simó-Mirabet, P., Perera, E., Calduch-Giner, J. A., Afonso, J. M., and PérezSánchez, J. (2018). Co-expression analysis of sirtuins and related metabolic biomarkers in juveniles of Gilthead sea bream (Sparus aurata) with differences in growth performance. Front. Physiol. 9:608. doi: 10.3389/fphys.2018.00608

Takle, H., and Castro, V. (2013). "Molecular adaptive mechanisms in the cardiac muscle of exercised fish," in Swimming Physiology of Fish, eds A. Palstra, and J. Planas, (Heidelberg: Springer).

Velázquez, M., Zamora, S., and Martínez, F. J. (2004). Influence of environmental conditions on demand-feeding behaviour of gilthead seabream (Sparus aurata). J. Appl. Ichthyol. 20, 536-541. doi: 10.1111/j.1439-0426.2004.00613.x

Vera, L. M., Montoya, A., Pujante, I. M., Pérez-Sánchez, J., Calduch-Giner, J. A., Mancera, J. M., et al. (2014). Acute stress response in gilthead sea bream (Sparus aurata L.) is time-of-day dependent: physiological and oxidative stress indicators. Chronobiol. Int. 31, 1051-1061. doi: 10.3109/07420528.2014.945646

Conflict of Interest: The authors declare that the research was conducted in the absence of any commercial or financial relationships that could be construed as a potential conflict of interest.

Copyright $\odot 2021$ Palstra, Arechavala-Lopez, Xue and Roque. This is an open-access article distributed under the terms of the Creative Commons Attribution License (CC BY). The use, distribution or reproduction in other forums is permitted, provided the original author(s) and the copyright owner(s) are credited and that the original publication in this journal is cited, in accordance with accepted academic practice. No use, distribution or reproduction is permitted which does not comply with these terms. 